\title{
PENTINGNYA PENGETAHUAN MASYARAKAT TENTANG KESEHATAN JIWA DI DUSUN CIMAMUT KABUPATEN CIAMIS
}

\section{THE IMPORTANCE OF COMMUNITY KNOWLEDGE ABOUT THE MENTAL HEALTH IN THE CIMAMUT VILLAGE OF CIAMIS DISTRICT}

\author{
Daniel Akbar Wibowo*, Dini Nurbaeti Zen \\ Fakultas Ilmu Kesehatan Universitas Galuh Ciamis \\ *Email: danielakbarwibowo@yahoo.co.id \\ (Diterima 11-03-2020; Disetujui 26-03-2020)
}

\begin{abstract}
ABSTRAK
Sehat adalah keadaan seseorang sempurna baik fisik, mental maupun sosial, tidak hanya terbebas dari penyakit atau kelamahan atau kecacatan. Menurut data dari WHO tahun 2016, terdapat sekitar 60 juta orang terkena bipolar, 47,5 juta terkena dimensia, 35 juta orang terkena depresi, serta 21 juta terkena skizofrenia. Di Indonesia, gangguan jiwa terus bertambah dengan berbagai faktor predisposisi diantaranya faktor biologis, psikologis dan sosial. Hal ini berdampak pada penambahan beban pemerintah dan penurunan kualitas sumber daya manusia dalam jangka panjang. Di Indonesia prevalensi ganggunan mental emosional dengan gejala depresi dan kecemasan untuk usia 15 tahun ke atas mencapai sekitar 6,1\% dari jumlah penduduk Indonesia. Sedangkan prevalensi gangguan jiwa berat, seperti skizofrenia mencapai sekitar 400.000 orang atau sebanyak 1,7 per 1.000 penduduk. Gangguan jiwa ini sangat berbahaya walaupun tidak langsung menyebabkan kematian, namun akan menimbulkan penderitaan yang mendalam bagi individu dan beban yang berat bagi keluarga. Tujuan kegiatan pengabdian masyarakat ini adalah untuk meningkatkan pengetahuan masyaraakat dan keluarga yang menjadi binaan khususnya bagaimana cara perawatan dan menjaga kesehatan jiwa setiap masyarakat serta merawat anggota masyarakat yang mengalami gangguan jiwa. Metode dalam kegiatan ini adalah ceramah, diskusi, dan juga simulasi. Luaran yang dihasilkan kegiatan pengabdian kepada masyarakat ini pemberdayaan masyarakat tentang kesehatan jiwa. Hasil yang dicapai dalam pengabdian ini adalah meningkatnya pengetahuan masyarakat tentang masalah kesehatan jiwa di lingkungan sekitarnya. Kesimpulannya pengabdian kepada masyarakat ini telah dilaksanakan dan berdasarkan hasil evaluasi pelaksanaan kegiatan maka diketahui bahwa terjadi peningkatan pengetahuan keluarga tentang masalah orang dengan gangguan jiwa (ODGJ) yang terjadi di sekitar lingkungannya
\end{abstract}

Kata kunci: Orang Gangguan Jiwa, Penyuluhan, Cimamut

\section{ABSTRACT}

Health is a condition when a person is in a perfect condition both physically, mentally and socially, not only from the disease or weakness or disability. According to data from the World Health Organization (WHO) in 2016, there were around 60 million affected by bipolar disorder, 47.5 million affected by dementia, 35 million affected by depression, and 21 million affected by schizophrenia. Cases of mental disorders in Indonesia continue to growth with various predisposing factors including biological, psychological and social factors. This has an impact on increasing the burden on the government and decreasing the quality of human resources in the long run. In Indonesia the prevalence of mental emotional disorders with symptoms of depression and anxiety for ages 15 and older reaches around $6.1 \%$ of the population of Indonesia. While the prevalence of severe mental disorders, such as schizophrenia reaches around 400,000 people or as much as 1.7 per 1,000 population (Riskesdas, 2018). The methods used in this activity are lectures, discussions and also simulations. The output produced in this community service is community empowerment about mental health. The results achieved in this service are increasing public knowledge about mental health issues in the surrounding environment. The conclusion is that community service activities have been carried out and based on the results of the evaluation of the implementation of the activities it is known that there is an increase in family knowledge about the problems of people with mental disorders (ODGJ) that occur around their environment.

Keywords: People with Mental Disorders, Services, Cimamut

PENDAHULUAN

Orang yang mengalami gangguan jiwa di dunia ini sudah banyak dan bahkan di Indonesia pun banyak penderita gangguan Jiwa baik dari kalangan remaja, dewasa, anak- 
anak sampai orangtua atau lansia mengalami gangguan tersebut. Menurut Videbeck dalam Prabowo (2014), gangguan jiwa adalah keadaan emosi, psikologis, dan sosial yang terpandang dari hubungan komunikasi antar dua orang yang tidak terpenuhi tindakan dan pertahanan yang baik, sesuatu yang dapat dipahami dalam diri yang baik dan keseimbangan emosi yang dalam.

Selain masalah gangguan jiwa, ada juga masalah psikososial yang biasa terjadi di kalangan masyarakat Indonesia. Masalah psikososial merupakan masalah yang banyak terjadi di masyarakat. Psikososial adalah suatu kondisi yang terjadi pada individu yang mencakup aspek psikis dan sosial atau sebaliknya. psikososial berarti menyinggung relasi sosial yang mencakup factor-faktor psikologi. Dari definisi di atas, masalah psikososial adalah masalah yang terjadi pada kejiwaaan dan sosialnya. Psikososial (Psychosocial) adalah hubungan antara kesehatan mental atau emosional seseorang dengan kondisi sosialnya. Istilah psikososial merupakan gabungan antara psikologis dan sosial. Dengan demikian, pengertian perkembangan psikososial adalah perkembangan yang berkaitan dengan emosi atau mental seseorang dalam berhubungan dengan orang lain. Jadi, perkembangan psikososial merupakan perubahan atau perkembangan kepribadian yang berkaitan dengan hubungan sosial

Menurut data dari World Health Organization (WHO) tahun 2016, terdapat sekitar 60 juta orang terkena bipolar, 47,5 juta terkena dimensia, 35 juta orang terkena depresi, serta 21 juta terkena skizofrenia. Di Indonesia, kasus gangguan jiwa terus bertambah dengan berbagai faktor predisposisi diantaranya factor biologis, psikologis dan sosial. Hal ini berdampak pada penambahan beban pemerintah dan penurunan kualitas sumber daya manusia dalam jangka panjang. Di Indonesia prevalensi ganggunan mental emosional dengan gejala-gejala depresi dan kecemasan untuk usia 15 tahun ke atas mencapai sekitar $6,1 \%$ dari jumlah penduduk Indonesia. Sedangkan prevalensi gangguan jiwa berat, seperti skizofrenia mencapai sekitar 400.000 orang atau sebanyak 1,7 per 1.000 penduduk (Riskesdas, 2018).

Banyak masalah-masalah psikososial yang dihadapi oleh keluarga dan masyarakat khususnya daerah perkotaan maupun pedesaan. Menurut Gerald (1983) dalam Hidayati (2018), keluarga menyediakan 3 fungsi dasar sebelum, selama dan setelah masa remaja. 3 fungsi ini tidak sepenuhnya dapat digantikan oleh peergroups/struktur sosial yang lain sepanjang hidup. 3 fungsi tersebut adalah: 
1. Keluarga menyediakan ikatan emosi

Kohesi ini atau ikatan emosi membuat kondisi untuk identifikasi dengan kelompok dasar yang utama dan meningkat secara emosional, intelektual dan kedekatan fisik.

2. Keluarga menyediakan model kemampuan adaptasi.

Keluarga mengilustrasikan melalui fungsi dasar bagaimana sebuah struktur kekuatan dapat berubah, bagaimana peran hubungan dapat berkembang dan begaimana peraturan hubungan dapat terbentuk. Remaja yang memiliki pengalaman tipe keluarga yang rigid (rendah tingkat adaptasinya) cenderung terinternalisasi gaya interaksi yang rigid. Sebaliknya, terlalu banyak kemampuan adaptasi dapat membuat gaya \&lsquo; chaotic\&rsquo;. Keseimbangan penting untuk fungsi ini, hal yang sama juga dengan kohesi.

3. Keluarga menyediakan sebuah jaringan komunikasi.

Melalui pengalaman dimana individu belajar seni dari pembicaraan, interaksi, mendengarkan dan negosiasi.

Pengkajian psikososial pada keluarga dilakukan di RT 14 Dusun Cimamut Desa Mekarjadi Kecamatan Sadannaya Kabupaten Ciamis. Berdasarkan hasil studi pendahuluan terdapat beberapa orang di masyarakat yang mengalami kecemasan dan menunjukan gejalagejala depresi. Sedangkan yang mengalami gangguan kejiwaan di Dusun Cimamut didapatkan ada 5 orang. Masalah Psikososial di RT 14 di Dusun Cimamut terdapat 15 orang.

\section{BAHAN DAN METODE}

Kegiatan pertama yang dilakukan adalah melaksanakan identifikasi permasalahan yang dialami oleh masyarakat dan keluarga tentang kesehatan jiwa. Permasalahan permasalahan yang telah diidentifikasi kemudian dilakukan analisis dan hasil analisis kemudian disusun dalam skala prioritas masalah yang harus diselesaikan. Masalah yang terpilih sebagai prioritas utama kemudian diselesaikan bersama dengan keluarga dan masyarakat dengan pemberian pendidikan kesehatan dan menggunakan metode ceramah,diskusi, dan simulasi. Jumlah populasi dalam kegiatan ini adalah 62 orang peserta yang datang pada waktu penyuluhan, dan dilakukan pemberian kuesioner sebagai pretest untuk mengetahui sejauh mana pengetahuan peserta ketika sebelum melakukan penyuluhan, setelah selesai penyuluhan peserta diberikan lagi kuesioner pertanyaan yang disebut post test. Data yang diperoleh dari kuesioner selanjutnya dilakukan analisis menggunakan uji $\mathrm{t}$ berpasangan dan uji korelasi regresi 


\section{HASIL DAN PEMBAHASAN}

Kegiatan pengabdian kepada masyarakat yang telah dilaksanakan adalah identifikasi permasalahan yang dihadapi oleh masyarakat dan keluarga ODGJ tentang kesehatan jiwa di RT 14 Dusun Cimamut Desa Mekarjadi Kecamatan Cijeunjing. Selanjutnya dilakukan analisis data hasil identifikasi permasalahan keluarga dalam mengatasi kecemasan di rumah dan menetapkan skala prioritas pada masalah yang telah ditemukan, serta melakukan pendidikan kesehatan sebagai salah satu solusi permasalahan prioritas yang dialami oleh keluarga di rumah.

Tabel 1. Distribusi Frekwensi Skrining Gangguan Jiwa Berdasarkan Kategoridi Dusun Cimamut Desa Mekarjadi Kecamatan Sadananya Ciamis $(\mathbf{n}=62)$

\begin{tabular}{llcc}
\hline No & \multicolumn{1}{c}{ Kategori } & Frekuensi & Persentase \\
\hline 1 & Sehat jiwa & 47 & 76 \\
2 & Cemas & 9 & 14 \\
3 & Depresi & 5 & 8 \\
4 & Psikoaktif/ narkoba & 0 & 0 \\
5 & Gangguan Psikotik & 1 & 2 \\
6 & Post traumatic stress & 0 & 0 \\
& disorder & & $\mathbf{1 0 0 \%}$ \\
\hline Jumlah & $\mathbf{6 2}$ & \\
\hline
\end{tabular}

Sumber: Data Primer, 2019

Tabel 1 menunjukan bahwa 47 orang tergolong sehat jiwa (76\%), 9 orang tergolong cemas $(14 \%), 5$ orang tergolong depresi $(8 \%)$, dan 1 orang tergolong gangguan psikotik (1\%). Evaluasi proses penyuluhan tentang perawatan Kesehatan Jiwa di Dusun Cimamut Desa Mekarjadi Kecamatan Sadananya Ciamis tersaji pada Tabel 2.

Tabel 2. Evaluasi proses penyuluhan tentang perawatan Kesehatan Jiwa di Dusun Cimamut Desa Mekarjadi Kecamatan Sadananya Ciamis (n=62)

\begin{tabular}{lll}
\hline \multicolumn{1}{c}{ Katagori } & \multicolumn{1}{c}{ Sebelum Penyuluhan } & \multicolumn{1}{c}{ Setelah Penyuluhan } \\
\hline Pengetahuan keluarga & 25\% keluarga dapat & $85 \%$ keluarga dapat \\
tentang kesehatan jiwa & menjelaskan kesehatan jiwa bagi & menjelaskan pentingnya \\
bagi masyarakat yang & masyarakat yang mengalami & perawatan kesehatan jiwa \\
mengalami gangguan & gangguan psikososial di rumah & $\begin{array}{l}\text { yang tepat pada masalah } \\
\text { psikososial di rumah }\end{array}$ \\
psikososial di rumah & dengan tepat & $95 \%$ keluarga diakhir \\
Antusiasme keluarga & 80\% keluarga antusias dalam & kegiatan antusias \\
dalam mengikuti & mengikuti kegiatan & mengikuti kegiatan \\
kegiatan penyuluhan & & \\
\hline
\end{tabular}

Tabel 2 menunjukan bahwa terdapat peningkatan pemahaman masyarakat tentang kesehatan jiwa dan juga peningkatan antusias masyarakat dalam mengikuti kegiatan penyuluhan sebagai bentuk upaya masyarakat dalam menambah pengetahuan mereka. 
Tabel 3 Nilai Rata-rata Nilai Pre-test dan Post-test Pengetahuan Masyarakat Dusun Cimamut Tentang Kesehatan Jiwa Menjadi Energi Positif ( $n=62)$

\begin{tabular}{llccc}
\hline No & & Kategori & Frekwensi & Persentasi (\%) \\
\hline 1 & Pre Test & & 16 & 25 \\
2 & Post-Test & 46 & 85 \\
\hline Jumlah & $\mathbf{6 2}$ & $\mathbf{1 0 0}$ \\
\hline
\end{tabular}

Berdasarkan nilai rata rata kemampuan pengetahuan masyarakat tentang mengubah kecemasan menjadi energi positif di rumah mengalami peningkatan $60 \%$.

\section{PEMBAHASAN}

Perawatan kesehatan jiwa di Dusun Cimamut masih mengandalkan petugas kesehatan dan tidak secara mandiri untuk dilakukan perawatan oleh keluarga Berdasarkan fakta fakta permasalahan kesehatan jiwa tersebut, World Health Organization (WHO) dan World Federation for Mental Health (WFMH) berupaya menekankan penyelesaian permasalahan kesehatan jiwa dari akarnya, yang dituangkan ke tema Hari Kesehatan Jiwa Sedunia 2016. Mengambil tema Cimamut Sehat jiwa Sehat Raga dengan sub tema Jiwa yang Sehat Berawal dari Jiwa raga yang Sehat; maka pesan utama yang ingin disampaikan adalah bahwa setiap orang memiliki hak untuk dihargai dan mendapatkan perlakuan layak sesuai dengan harkat dan martabat sebagai manusia .

World Health Organitation (2001) menjelaskan bahwa gangguan jiwa merupakan sekumpulan gangguan pada fungsi pikir, emosi, perilaku dan sosialisasi dengan orang sekitar. Macam-macam gangguan jiwa (Maslim, 2008) diantaranya gangguan jiwa organik dan simtomatik, skizofrenia, waham, gangguan suasana perasaan, gangguan neuropatik, gangguan somatoform, sindrom perilaku yang berhubungan dengan gangguan fisiologis dan fisik, gangguan kepribadian dan perilaku masa dewasa, retardasi mental, gangguan perkembangan psikologis, gangguan perilaku dan emosional dengan onset masa anak dan remaja.

Angka kekambuhan skizofrenia mengalami kenaikan pada tahun 2017. Tingginya angka kekambuhan pada skizofrenia disebabkan karena beberapa faktor, salah satu faktor yang berperan sangat penting adalah hubungan pasien dengan keluarga (Prabowo, 2010). Sedangkan Videbeck (2013) dalam Widianti (2018) mendefinisikan gangguan jiwa berat sebagai gejala gangguan mental berat di mana seseorang kehilangan kemampuan untuk mengenali realitas, berhubungan dengan orang lain,dan berperilaku aneh. 
Peningkatan jumlah populasi penduduk dunia yang menderita gangguan jiwa menimbulkan dampak bagi keluarga dan masyarakat. Dampak yang ditimbulkan oleh gangguan jiwa dapat dibedakan menjadi dampak secara sosial dan dampak secara ekonomi. Dampak secara sosial dapat berupa pengucilan, hinaan, ejekan, dipisahkan dari lingkungan serta menimbulkan ketakutan masyarakat (Lee et al dalam Widianti, 2018). Sedangkan dampak secara ekonomi adalah menurunnya produktivitas pasien dengan gangguan jiwa dan caregivernya, adanya beban ekonomi dan menurunnya kualitas hidup (Sadock \& Sadock, 2007).

Besarnya beban yang harus ditanggung oleh individu, keluarga, dan masyarakat akibat meningkatnya gangguan jiwa ini perlu mendapat perhatian yang serius dengan berupaya meningkatkan pengetahuan dan pemahaman tentang gangguan jiwa agar mampu berupaya untuk mencegah dan mengatasinya. Upaya pencegahan dan penanggulangan gangguan jiwa di masyarakat adalah tugas bersama masyarakat beserta seluruh pihak diantaranya petugas kesehatan yang berada di wilayah kerja puskesmas setempat. Upaya pencegahan ini dapat dilakukan dengan beberapa tahapan. Tahapan pertama adalah dengan melakukan pendekatan kepada perangkat wilayah dan tokoh masyarakat setempat. Tahap berikutnya adalah melakukan psikoedukasi kepada perangkat dan tokoh masyarakat wilayah setempat sehingga didapatkan pemahaman yang sama antara petugas kesehatan dan perangkat wilayah serta tokoh masyarakat tentang pentingnya pengetahuan dan pemahaman tentang kesehatan jiwa sehingga mampu melakukan upaya pencegahan dan penanggulangan ganguan jiwa. Tahap berikutnya adalah perangkat wilayah dan tokoh masyarakat menetapkan wakil dari wilayah bertugas menjadi fasilitator bagi masyarakat dalam upaya penanggulangan gangguan jiwa di masyarakat.

Perwakilan masyarakat yang mengurusi masalah kesehatan jiwa masyarakat ini disebut sebagai kader kesehatan jiwa. Kader kesehatan jiwa yang telah ditetapkan mengikuti pelatihan kader kesehatan jiwa untuk meningkatkan pengetahuan dan keterampilan dalam mencegah dan menanggulangi gangguan jiwa di masyarakat sesuai dengan peran dan fungsinya, tugas selanjutnya yang diemban oleh kader kesehatan jiwa adalah melakukan deteksi dini gangguan jiwa sebagai langkah awal untuk melakukanpemetaan masalah kesehatan jiwa di masyarakat sehingga dapat ditentukan langkah langkah pencegahan dan penanggulangan lebih lanjut. Peran yang dijalankan oleh kader kesehatan jiwa ini akan dapat berjalan dengan optimal ketika ada dukungan optimal pula oleh petugas kesehatan di puskesmas terkait dan masyarakat secara umum termasuk didalamnya keluarga klien dengan 
gangguan jiwa, sehingga harapan terwujudnya masyarakat sehat jiwa raga dapat menjadi sebuah kenyataan.

\section{KESIMPULAN}

Kegiatan Pengabdian Kepada Masyarakat ini telah dilaksanakan dan berdasarkan hasil evaluasi pelaksanaan kegiatan maka diketahui bahwa terjadi peningkatan pengetahuan keluarga tentang pentingnya energi positif untuk mengatasi kecemasan pada masyarakat Dusun Cimamut.

\section{UCAPAN TERIMA KASIH}

Dengan selesainya PKM ini kami ucapkan terima kasih kepada masyarakat Dusun Cimamut, kader, tokoh masyarakat, puskesmas Sadananya, dan perangkat desa yang telah ikut serta dalam mensukseskan kegiatan ini.

\section{DAFTAR PUSTAKA}

Depkes RI. (2019). Riset Kesehatan Dasar 2018. Badan Penelitian dan Pengembangan Kesehatan Republik Indonesia. Jakarta.

Hidayati, N. O., Widianti, E., Sriati, A., Sutini, T., Rafiyah, I., Hernawaty, T., \& Suryani, S. (2018). Pelatihan Perencanaan Diri Terhadap Orientasi Masa Depan Remaja di Lembaga Pembinaan Khusus Anak (LPKA). Media Karya Kesehatan, 1(2): 155-161.

Maslim, R. (2008). Buku Saku Diagnosis Gangguan Jiwa (PPDGJ III). Bagian Ilmu Kedokteran Jiwa FK-Unika Atmajaya. Jakarta.

NIMH. (2000). American Psychiatric Associations. http://www.nimh.nih.gov/statistics

NIMH. (2011). Prevalence of Mental Ilness by Disorder. http://www.nimh.nih.gov/statistics Prabowo, E. (2014). Konsep \& Aplikasi Asuhan Keperawatan Jiwa. Yogyakarta: Nuha Medika.

Saddock, B.J dan Saddock, V.A (2007). Kaplan and Saddock's synopsis of psychiatry: Behavioral science/clinical psychiatry. 10th Ed. Lippincott William \& Wilkins.

WHO. (2006). The Lancet. London: Elsevier Properties SA.

WHO (2010). Maternal Mortality. Geneva: World Health Organization. 